\title{
Quality of life in patients with gastroschisis is comparable with the general population: A questionnaire survey
}

\author{
Barbora Frybovaa ${ }^{a}$ Alena Kokesova ${ }^{\mathrm{a}}$, Daniela Zemkova ${ }^{\mathrm{b}}$, Vladimir Mixac, Radovan Vlk ${ }^{\mathrm{d}}$, Michal Rygl ${ }^{\mathrm{a}}$
}

\begin{abstract}
Aim. To evaluate long-term quality of life and somatic growth of patients with gastroschisis and compare them with the general population.

Methods. We performed a questionnaire survey of the quality of life of our patients treated between 2004-2012.

Results. A questionnaire was sent to our 56 patients with gastroschisis, 38 mothers of patients (68\%) responded to the questionnaire. 33 of 38 mothers claim that the quality of life of their child is very good, 4 of them responded that it is good. 1 mother confessed that the quality of life was very poor. Anthropometric data show comparable results with the standard population except for patients of 1 year of age who still have lower weight $(\mathrm{P}<0.001)$ and body height in the 5th percentile and patients of 3 years of age who are also significantly thinner. 13\% of patients in our study group have gastrointestinal problems. 9 patients (24\%) attend follow-up at the neurological center (Attention Deficit Hyperactivity Disorder $n=6$, mental retardation $n=1$, dysarthria $n=2$ ), however, overall intellectual abilities are within normal range. 7 patients underwent surgery for umbilical $(n=3)$ or inguinal hernia $(n=4), 2$ patients were operated on for undescended testicles, 3 patients were operated on for an adhesive ileus. $92 \%$ of mothers are very satisfied with the cosmetic result of the scar.

Conclusion. The study has shown that the majority of patients after operation of gastroschisis have a very good quality of life without limitation in comparison with the general population. The presented anthropometric data confirm that the development of patients with gastroschisis is favourable.
\end{abstract}

Key words: gastroschisis, long term follow-up, quality of life, anthropometric data

Received: September 7, 2016; Accepted: November 25, 2016; Available online: December 13, 2016 https://doi.org/10.5507/bp.2016.059

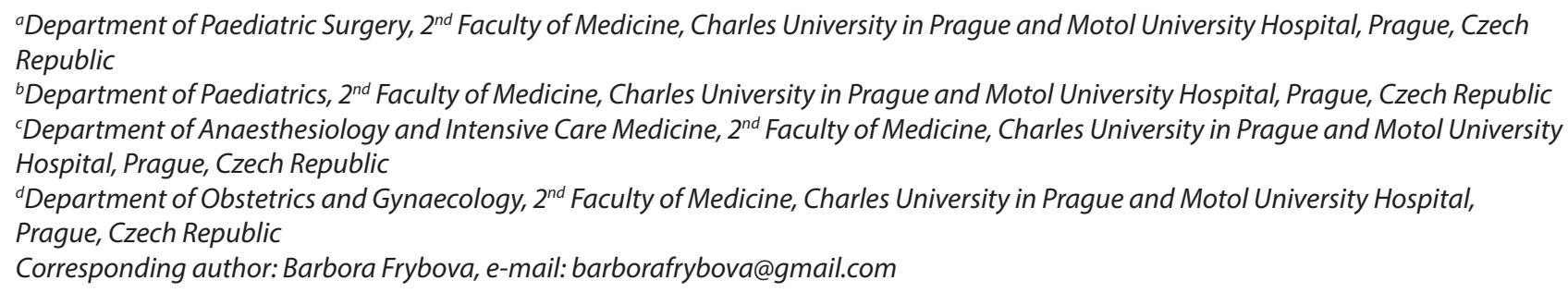

\section{INTRODUCTION}

Gastroschisis is the most common prenatally diagnosed congenital defect of the abdominal wall. Patients with gastroschisis have shown improving rates of survival during the last decades because of upgrades in perinatal and perioperative care. The survival rate of neonates with gastroschisis is currently over $95 \%$ ( ref. $^{1}$ ). Nowadays, our attention is not focused only on mere survival, but also on the long term results of the treatment and the quality of life of the survivors. Analysis of long term results given in the form of feedback could contribute to further improvement of the treatment of children with gastroschisis and is significantly important to parents during prenatal counselling. Their prenatal questions are targeted at the quality of life for their child and what that may entail. Therefore, we decided to evaluate the long-term quality of life and anthropometric data of our patients and compare them with the standard population.

\section{MATERIAL AND METHODS}

We included in the questionnaire survey study all patients with gastroschisis who were operated on at our Department of Paediatric Surgery between 2004-2012. A questionnaire was sent to our 56 former patients with gastroschisis. It consisted of 18 questions about their general health condition, surgeries underwent and hospitalisation, follow-up in the special ambulances, growth disorder, changes in bowel habits and constipation, problems with alimentation, allergies, chronic medication and cosmetic result of the scar. Other questions were about psychomotor development and the type of attended school or nursery.

The questionnaire also included a table with the weight and height of the patients at 3 months of age, 1 year, 1.5, 3, 5, 7 and 9 years of age. The measurements were collected in the ambulances of General Paediatrician Practitioners at the time of regular preventive examina- 
tions. The data of the gastroschisis group were statistically evaluated and compared with the general population by a clinical anthropologist. The data were converted into a standard deviation score (SDS) of body height, weight and BMI according to the latest available Czech standards - VI. Nationwide anthropological survey 2001 ( ref. $^{2}$ ). The mean body height, weight and body mass index (by means of SDS) were tested against the expected value of 0 using a one-sample t-test. A $P<0.05$ was regarded as significant.

Finally, patients' mothers were asked what the current biggest problem of their child was and how they personally valued the quality of life of their child between a score of 1 (very good quality) to 4 (poor quality of life).

38 patients' mothers (68\%) responded the questionnaire.

The study design was approved by the Ethical Committee of the $2^{\text {nd }}$ Medical Faculty Charles University, Prague.

\section{RESULTS}

\section{Patient characteristics}

Between 2004-2012 we treated 58 patients with gastroschisis, 2 of them died during early months of life so these we excluded from our study. The survival rate of our study is $96.5 \%$.

54 of 56 patients $(96 \%)$ from our study were prenatally diagnosed, 25 patients (45\%) were delivered via Caesarean section but this fact did not correlate with their future outcome. Maternal age ranged from 15 to 38 years with a mean age of 24 years.

In our study group there were 4 patients with complex gastroschisis, 52 with simple gastroschisis. 46 patients underwent primary closure ( $82 \%), 10$ patients (18\%) were treated by stepwise reconstruction.

\section{The questionnaire survey results}

$68 \%$ of mothers ( 38 of total 56 ) responded to the questionnaire.

7 patients underwent surgery for umbilical $(n=3)$ or inguinal hernia $(n=4), 2$ patients were operated on for undescended testicles, 3 patients were operated on for an ileus due to adhesions ( 1 of them had an appendectomy at the same time).

7 patients attend follow-up at special centers: 3 patients regularly visit an allergologist, 2 patients visit proctological ambulance because of chronic constipation, 2 patients a nephrologist ( 1 because of family history of benign familial hematuria, another one because of hypotonia of renal pelvis). 9 patients (24\%) attend follow-up at the neurological center (ADHD $n=6$, mental retardation $\mathrm{n}=1$, dysarthria $\mathrm{n}=2$ ).

8 mothers confess problem with alimentation: 7 mothers $(18 \%)$ think that their child eats less than the general population, 1 patient must be fed by an assistant. Nevertheless, the anthropometric measurements have not shown any signs of malnutrition in these children.

8 patients of our study have had during their life at least one episode of constipation which required a visit to a doctor. 3 of these patients have had chronic constipation pharmacologically treated ( $8 \%$ ) and 2 patients (older than 5 years of age) still wear diapers, that means $13 \%$ of patients in our study group have gastrointestinal problems.

All patients except one regularly visit nursery or school appropriate for their age and their school results and intellectual ability are completely comparable with the normative means. One patient with mental retardation attends a special school with an assistant.

5 mothers admitted allergies of their children in the questionnaire: specifically allergies to penicillin, gluten, lactose, fur, dust.

5 patients from our study group take medication regularly (diazepam, levocetirizine, lactulose, albuterol).

33 of 38 mothers claim that the quality of life of their child is very good, 4 of them responded that it is good. 1 mother answered that the quality of life of her boy was very poor. This boy (nowadays 11 years old) had the worst outcome of all our patients. He was born from an unfollowed pregnancy with intestinal atresia and the abdominal defect was closed by stepwise reconstruction with 3 reoperations for adhesive ileus. His psychomotor development corresponds with a 1-year-old child. His mental deficit was caused by perinatal asphyxia (knotting of umbilical cord around the neck).

34 from 38 patients in our study group have the umbilicus conserved. 35 of 38 mothers are very satisfied with the cosmetic result of the scar, 2 mothers don ' $t$ consider the scar important so they didn't answer the question and 1 mother is considering scar revision in the future.

The current most serious problems (complaints) of the child were presented: chronic constipation $n=3$ (these patients have to use laxatives every day), ADHD ( $n=1)$, dysarthria $(n=2)$, dysgraphia $(n=1)$, umbilical hernia $(n=1)$, psychomotor retardation $(n=1)$, absence of an umbilicus causes distress at school $(n=1)$.

\section{Anthropometric data}

The body weight, height and body mass index of our study group were compared with the standard Czech population and expressed by means of SD score for age and $\operatorname{sex}^{2}$. The body mass index is calculated in children older than 3 years, because in younger children the results can be misleading.

The majority of patients of our study were premature. The median of gestational age is 35.5 weeks ( $\mathrm{min}$. 28.6, max. 38.4 weeks), 26 patients (from 38 who responded to the survey) were born before 37 . week of gestation. Mean birth weight was $2264 \pm 466 \mathrm{~g}$ and the majority of patients were appropriate for gestational age (median in $25^{\text {th }}$ percentile). Only $3 / 38$ patients $(7.9 \%)$ were small for gestational age.

The body weight at 3 months of age was $4.6 \pm 0.9 \mathrm{~kg}$ (min. $2.7 \mathrm{~kg}$, $\max 6 \mathrm{~kg})$, that is $-1.9 \pm 1.8 \mathrm{SD}(P<0.001)$. After gestational age correction the body weight was -0.6 \pm 1.8 and the difference from the standard population was not statistically significant $(P=0.07)$.

Between 3 months and 1 year of age we noticed weight and height improvement which was statistically significant $(P=0.003),-0.9 \pm 1.1 \mathrm{SD}$. This result reflects the physiolo- 
Table 1. Anthropometric data.

\begin{tabular}{lccccc}
\hline Age & Body height $(\mathrm{cm})$ & Body height $(\mathrm{SDS})$ & Body weight $(\mathrm{kg})$ & Body weight $(\mathrm{SDS})$ & BMI (SDS) \\
\hline 3 months & $55.8 \pm 3.5$ & $-1.8 \pm 1.3^{* * *}$ & $4.28 \pm 0.87$ & $-1.9 \pm 1.8^{* * *}$ & - \\
1 year & $75 \pm 3.1$ & $-0.4 \pm 0.9 *$ & $9.2 \pm 1.2$ & $-0.9 \pm 1.1^{* * *}$ & - \\
1.5 year & $83.3 \pm 4.4$ & $0.2 \pm 1.1$ & $11.3 \pm 1.8$ & $-0.3 \pm 1.2$ & - \\
3 years & $97 \pm 4.8$ & $-0.3 \pm 0.9$ & $14.1 \pm 1.8$ & $-0.7 \pm 1.1 * *$ & $-0.7 \pm 1.1^{* *}$ \\
5 years & $110.7 \pm 5.2$ & $-0.3 \pm 1.1$ & $18.4 \pm 3$ & $-0.4 \pm 0.3$ & $-0.4 \pm 1.3$ \\
7 years & $123.1 \pm 7.5$ & $-0.3 \pm 1.4$ & $22.8 \pm 3.9$ & $-0.5 \pm 1.3$ & $-0.4 \pm 1$ \\
9 years & $115 ; 135 ; 139$ & $-3.8 ;-0.1 ; 0.4$ & $19.9 ; 25.6 ; 31$ & $-3.3 ;-0.7 ; 0.2$ & $-0.9 ;-0.9 ; 0.1$ \\
\hline
\end{tabular}

${ }^{*} P$ value $<0.05,{ }^{* * P} P<0.01,{ }^{* * *} P<0.001$

gical development of preterm children, but our patients of 1 year of age have still lower weight in comparison with the standard population $(P<0.001)$, the body height is in $5^{\text {th }}$ percentile.

The height and weight of our patients older than 1.5 years of age is completely comparable with the standard population except for patients of 3 years of age, who were significantly thinner (Table 1).

We gained only 3 values of height and weight of our 9-year-old patients, who are also thinner for their age, but this is a small number for performing of statistical analysis.

\section{DISCUSSION}

Gastroschisis, one of the most common prenatally diagnosed congenital malformations, is characterized by eventration of intestinal loops through the abdominal wall defect. Total length of the intestines is shortened; intestinal atresia is present in $10-15 \%$ with risk of short bowel syndrome in extensive intestinal atresia. Motility and absorption capacity of prenatally affected intestine is reduced in early postnatal period. Restoration of full complex function in prenatally damaged intestine and achievement of full oral intake usually takes several weeks or months. Analysis of long term results could contribute to better understanding of bowel development and somatic growth in children with gastroschisis and it provides important prognostic data for parents during prenatal consulting. All pregnant women with diagnosed gastroschisis should be invited to a referral center for prenatal consulting and the actual study of long-term follow-up of former patients is needed.

The contemporary literature shows that the survival of patients with gastroschisis is excellent - over 95\% (ref. ${ }^{1}$ ). Despite the greater incidence of "minor" problems when compared to a healthy population, the health status and the quality of life of children with gastroschisis seem to be satisfactory ${ }^{3-7}$. Conversely, Sawicka et al. published that 7 from 23 patients of his study population died: $70 \%$ survival rate ${ }^{8}$. The majority of mothers $(87 \%)$ who took part in our survey valued the quality of life as very good. The prenatal counselling helps to prepare mothers for possible future complications related to the diagnosis of

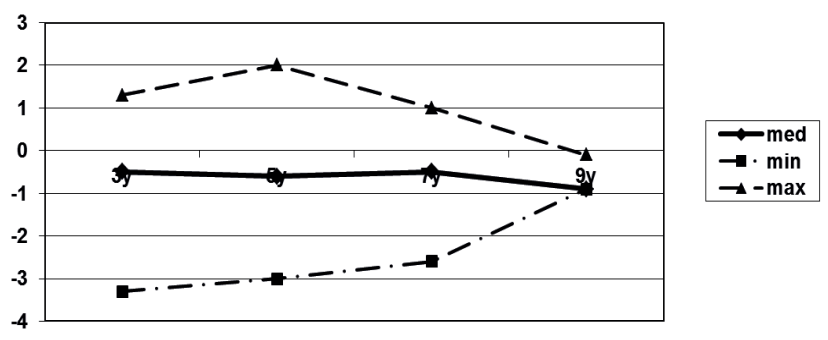

Fig.1. Body mass index (SDS) in comparison with the standard Czech population ( 0 level) in 3, 5, 7 and 9 years.

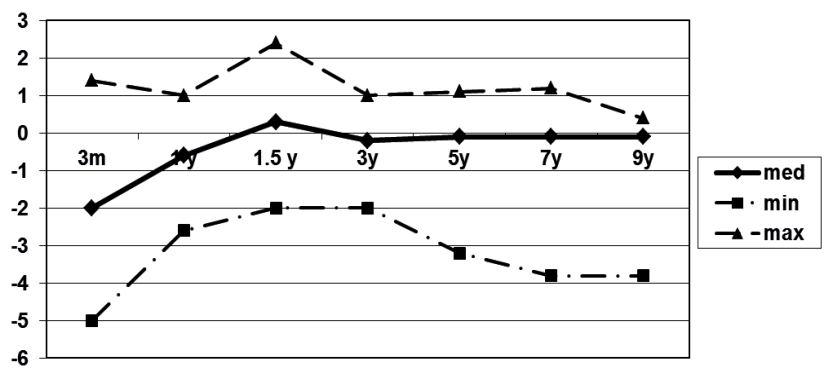

Fig. 2. Body height (SDS) in comparison with the standard Czech population (0 level) in 3 months, 1 year, 1.5 years, 3, 5, 7 and 9 years.

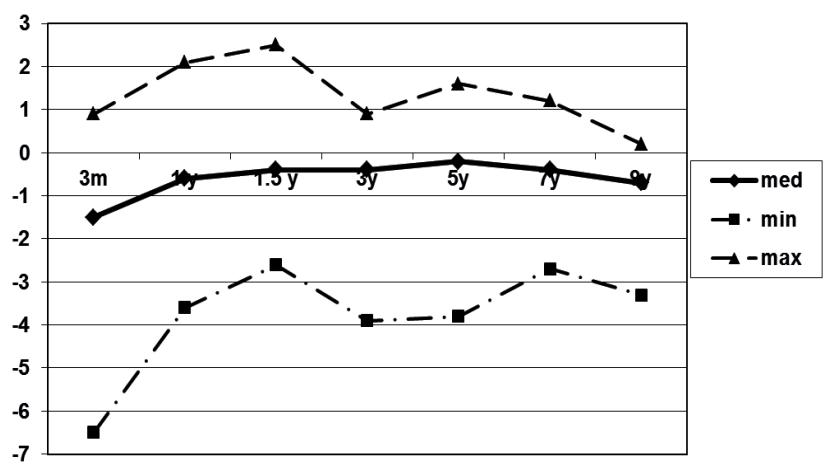

Fig. 3. Body weight (SDS) in comparison with the standard Czech population (0 level) in 3 months, 1 , year, 1.5 years, 3 , 5,7 and 9 years. 
gastroschisis, so it is possible that this fear in prenatal period is improving later evaluation of the quality of life. Also, the presented anthropometric data confirm that the development of patients with gastroschisis is favourable, which is in compliance with published literature.

All patients (except for one with mental retardation) from our study visit nursery or school like the general population. We have similar results to Lunzer et al. (ref. ${ }^{9}$ ) who claimed that after discharge, all their patients with gastroschisis were developing normally except for one child with history of prenatal asphyxia, who showed signs of mental retardation. Very good intellectual abilities is also described by Harris et al. in their cohort study ${ }^{10}$. However, 6 patients from our study group suffer from ADHD, 2 from dysarthria and 1 boy has mental retardation. A variety of prospective animal models and restrospective human studies demonstrate a harmful effect of early life exposure to anaesthetic drugs ${ }^{11-13}$. Ing et al. in their cohort study showed that even one exposure of general anaesthesia could affect the development of speech ${ }^{11}$. Thus, the differences in language and cognitive function should be charged to account of anaesthesia exposure in neonatal age, it does not seem to be linked to diagnosis of gastroschisis itself.

Henrich et al. describe in their study that $75 \%$ of the children had no gastrointestinal problems, almost all the children from their study were of normal weight and height, and physical and intellectual development were delayed in only one third of the children; the surgical scar was rated as good or very good in about $80 \%$ of the cases $^{14}$. Our study population had no gastrointestinal problems in $87 \%$ and the scar is rated as very good in $92 \%$ of the cases. Both studies show very good numbers. Also, Davies et al. values the scar in his study and describes that the absence of umbilicus causes distress during childhood in $57 \%$ of his study population ${ }^{15}$. We noticed this problem only in 1 patient, but we always try to conserve the umbilicus at our department when it is possible: 34 from 38 patients (89\%) from our study group have the umbilicus conserved.

3 patients from our study group were operated on for an ileus due to adhesions $(7.9 \%, 1$ patient after stepwise reconstruction with the silo, 2 patients after primary closure). Ileus due to adhesions is a common postoperative complication, in the study of Piaseczna-Piotrowska et al. adhesions after laparotomy in children were present in 4.7\%. (ref. ${ }^{16}$ )

Limited number of patients included in our study and the relative low response rate of our survey (68\%) are the main weaknesses of our study. We also have a limited number of body-measurement values for 9-year-old children and further study of adolescents is needed. On the contrary, the measurements were taken by the General Paediatrician Practitioners so we consider the values credible. Regular preventive examinations with standardized measurement have been carried out in the Czech Republic since the 1960s.

\section{CONCLUSION}

Our study has shown that the majority of patients after operation of gastroschisis have a good quality of life without limitation in comparison with the general population. Overall intellectual abilities are within normal range. The anthropometric data confirm that the somatic development of patients with gastroschisis is favourable, further study of adolescents is needed. This conclusion is an important piece of information for prenatal counselling and is also energizing for the gastroschisis surgical and paediatric teams.

Acknowledgement: This article is supported by grant GA UK 159115, $2^{\text {nd }}$ Faculty of Medicine, Charles University in Prague.

Author contribution: All authors contributed equally to preparing the manuskript.

Conflict of interest statement: The authors state there are no conflicts of interest regarding the publication of this article.

\section{REFERENCES}

1. Feldkamp ML, Botto LD, Byrne JL, Krikov S, Carey JC. Clinical presentation and survival in a population-based cohort of infants with gastroschisis in Utah, 1997-2011, Am J Med Genet A 2016;170A(2):306-15. doi: 10.1002/ajmg.a.37437

2. Kobzova J, Vignerova J, Blaha P, Krejcovsky L, Riedlova J. The 6th nationwide anthropological survey of children and adolescents in the Czech Republic in 2001. Central European Journal Of Public Health 2004;12(3):126-30.

3. Guida E, Pini-Prato A, Mattioli G, Carlucci M, Avanzini S, Buffa P, Michelazzi A, Montobbio G, Jasonni V. Abdominal wall defects: a 33-year unicentric experience. Minerva Pediatr 2013;65(2):179-85.

4. Koivusalo A, Lindahl H, Rintala RJ. Morbidity and quality of life in adult patients with a congenital abdominal wall defect: a questionnaire surfy, J Pediatr Surg 2002;37(11):1594-601.

5. Kaiser MM, Kahl F, von Schwabe C, Halsband H. Omphalocele and gastroschisis. Outcome--complications--follow-up--quality of life. Chirurg 2000;71(10):1256-62.

6. Tunell WP, Puffinbarger NK, Tuggle DW, Taylor DV, Mantor PC. Abdominal wall defects in infants. Survival and implications for adult life. Ann Surg 1995;221(5):525-8; discussion 528-30.

7. Halsband $H$, von Schwabe $C$. Long term results and quality of life of children with omphalocele and gastroschisis. Langenbecks Arch Chir Suppl II Verh Dtsch Ges Chir 1989:951-5.

8. Sawicka E, Płoska-Urbanek B, Michalak J, Lenkiewicz T. Advances in treatment of congenital gastroschisis based on personal examinations. Med Wieku Rozwoj 2000;4(2):197-205.

9. Lunzer H, Menardi G, Brezinka C. Long-term follow-up of children with prenatally diagnosed omphalocele and gastroschisis. J Matern Fetal Med 2001;10(6):385-92.

10. Harris EL, Hart SJ, Minutillo C, Ravikumara M, Warner TM, Williams Y, Nathan EA, Dickinson JE. The long-term neurodevelopmental and psychological outcomes of gastroschisis: A cohort study. J Pediatr Surg 2016;51(4):549-53.

11. Ing C, DiMaggio CJ, Whitehouse A, Hegarty MK, Brady J, von UngernSternberg BS, Davidson A, Wood AJ, Li G, Sun LS. Long-term differences in language and cognitive function after childhood exposure to anesthesia. Pediatrics 2012;130(3):e476-85.

12. Aker J, Block RI, Biddle C. Anesthesia and the developing brain. AANA J 2015;83(2):139-47.

13. Chemaly M, El-Rajab MA, Ziade FM, Naja ZM. Effect of one anesthetic exposure on long-term behavioral changes in children. J Clin Anesth 2014;26(7):551-6. 
14. Henrich K, Huemmer HP, Reingruber B, Weber PG. Gastroschisis and omphalocele: treatments and long-term outcomes. Pediatr Surg Int 2008;24(2):167-73.

15. Davies BW, Stringer MD. The survivors of gastroschisis. Arch Dis Child $1997 ; 77(2): 158-60$.
16. Piaseczna-Piotrowska A, Jóźwiak A. lleus due to adhesions as a consequence of abdominal surgery in childhood - analysis of 94 cases. Med Wieku Rozwoj 2011;15(1):91-5. 